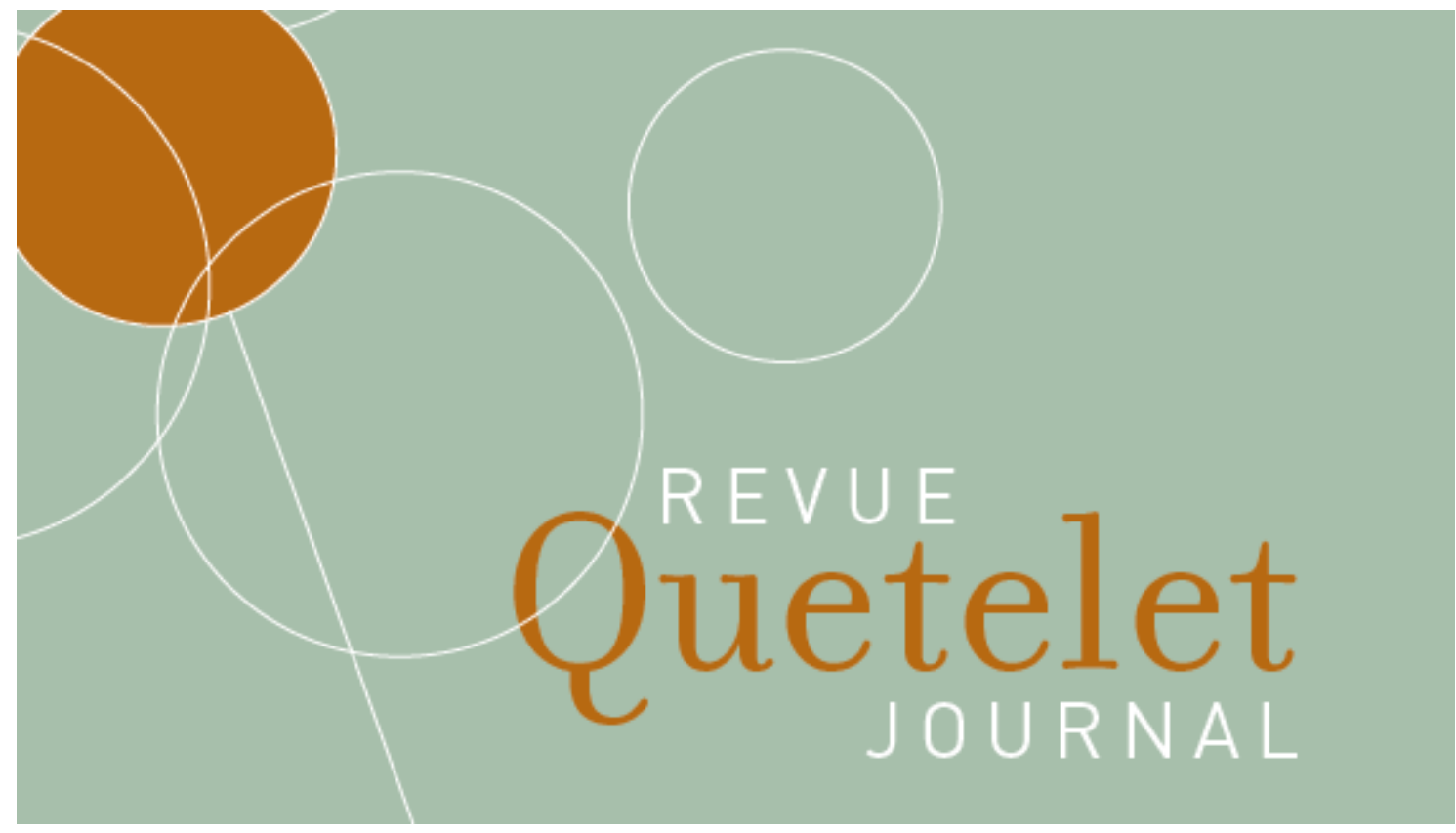

Vol. 6, n 1, avril 2018, pp. 73-97

DOI : $10.14428 /$ rqj2018.06.01.04

ISSN: 20349378

\title{
Estimating local mortality tables for small areas: An application using Belgian sub-arrondissements
}

Jon Anson

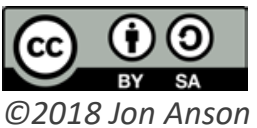

This work is licensed under a Creative Commons Attribution-NonCommercial 4.0 International License. You can share, adapt the material for non-commercial purposes provided that you give appropriate credit and indicate if changes were made. For details see https://creativecommons.org/licenses/by-sa/4.0/

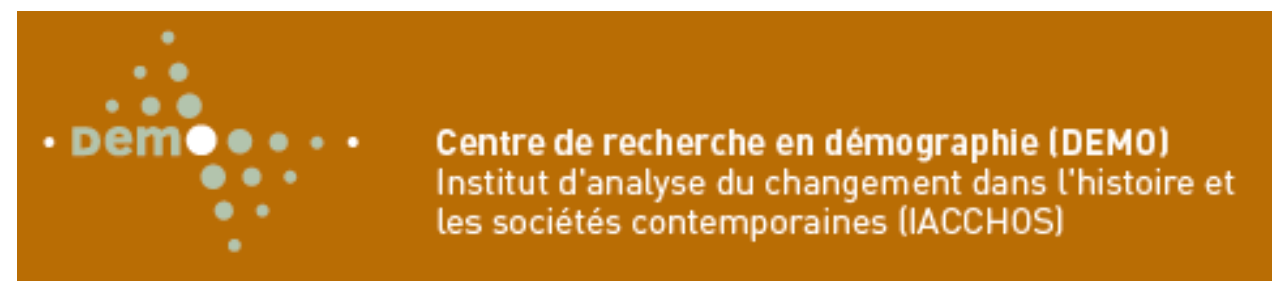





\title{
Estimating local mortality tables for small areas: An application using Belgian sub-arrondissements
}

\author{
JON ANSON ${ }^{1}$
}

\begin{abstract}
Résumé
L'indice standardisé de mortalité (SMR) peut fournir une bonne estimation du niveau relatif de mortalité à l'échelle locale et de son lien avec les conditions sociales locales. Mais si nous souhaitons comprendre les changements dans la répartition par âge de la mortalité lorsque la mortalité diminue, nous avons besoin d'une estimation de la courbe de mortalité locale. Mais ces informations ne sont pas exploitables dans le cas de petites populations, pour lesquelles le nombre de personnes dans chaque groupe d'âge et à fortiori le nombre de décès sont faibles et les erreurs d'estimation importantes. Une solution à ce problème consiste à estimer simultanément les taux de mortalité par âge pour toutes les sous-unités d'un pays donné, en utilisant le nombre de décès par âge et par sexe, pour chaque unité, en tant que données d'entrée. Les taux de mortalité nationaux serviront alors de modèle à partir duquel seront estimées les variations locales, par âge et par sexe, sur la base de la mortalité générale (RSM) et des conditions sociales locales. Nous recourrons à cette approche avec les données de 87 unités spatiales en Belgique pour construire des tables de mortalité au niveau local en utilisant un modèle multiniveau avec les données locales par âge et sexe comme unité de base et les données régionales par âge et sexe comme unité de deuxième niveau.

Les résultats indiquent que l'espérance de vie est étroitement liée au SMR, mais la forme spécifique de la courbe de mortalité - notamment aux âges de milieu de vie lorsque la mortalité est faible et aux âges plus élevés lorsqu'elle commence à augmenter - varie selon le niveau de mortalité et les conditions sociales.
\end{abstract}

Mots-clés

Belgique, mortalité, unités infranationales, courbe de mortalité, espérance de vie.

Abstract

Standardised mortality ratios (SMR) may give a good estimate of the relative level of mortality in a local area, and its relation to local social conditions, but if we wish to

1. Ben-Gurion University of the Negev, Israël. 
understand changes in the age distribution of mortality as mortality declines, we need an estimate of the local mortality curve. Such fine detail can be elusive when examining small populations for which the number of people in each age group is small, the number of deaths minuscule, and estimation errors are large. A possible solution to this problem is to estimate age specific mortality rates simultaneously for all the subunits of a particular country, using the reported number of deaths, by age and sex, for each unit as the input data. The national mortality rates then serve as a model from which local deviations, by age and sex, are estimated, on the basis of overall mortality (SMR) and local social conditions. We demonstrate this approach using data from 87 sub-national units in Belgium to construct local-level life tables, using a multilevel model with the local sex- and age-specific cells as units, nested within sex-age groups and regional units at the second level. The results indicate that life expectancy is closely related to SMR, but the specific shape of the mortality curve, in particular the range over which mid-life mortality is low and the age at which mortality begins to rise into senescence, varies by level of mortality and social conditions.

\section{Keywords}

Belgium, mortality, sub-national units, mortality curve, life expectancy.

\section{Introduction}

There is a long tradition of estimating small area levels of mortality and relating these to aggregate measures of the standard of living and other indices reflecting the conditions in which the population lives its life (Anson, 1988; Langford, Bentham, 1996; Yen, Kaplan, 1999; Santana et al., 2015). Given that the crude death rate gives a very poor estimate of the mortality risk in the population (Newell, 1988, Ch. 6), dependent as it is on the age distribution of the population, most of this work has been based on standardised measures. These have used direct standardisation for larger populations and indirect standardisation for smaller populations, for which age specific mortality rates cannot be reliably estimated (Rowland, 2003). Despite the criticism of indirect standardisation (Shryock et al., 1980, Ch. 14), these analyses have provided useful and consistent information concerning the relationship between the mean level of mortality in a population and standards of living (Stanners et al., 2014); family structure (Anson, 2010); pollution (Hystad et al., 2014); 
urbanisation and population density (Mahoney et al., 1990); income inequality (Stanistreet et al., 1999) and other area-level conditions.

Going beyond the mean level of mortality in the population, we may be interested in the way social conditions affect different age groups. Although there is a close correlation between mortality levels at different age groups, there are, nonetheless, important differences between populations even if they have a similar level of total mortality. Some will have particularly high levels of infant or child mortality relative to their level at higher ages; others will exhibit premature, and hence higher, levels of mortality at older ages, relative to their level of mortality at younger ages (Goldman, 1980; Coale et al., 1983; Anson, 1993). Indeed, the logic behind model mortality tables is precisely that a common mean level of mortality, as expressed in life expectancy at birth, does not necessarily imply a common age-distribution of the risk of death in the population (Petrioli, 1982; UN, 1982; Coale et al., 1983; Wilmoth et al., 2012). At different stages of the mortality transition, in different historical periods and under different sets of social conditions, there are always some age groups for which mortality declines faster than for others (Omran, 1971; Olshansky, Ault, 1986; Zhao et al., 2014) and the shape of the life table varies and cannot, consequently, be read off from the mean level of mortality, or life expectancy. At relatively low levels of mortality, such as is to be found in the various regions and sub-regions of Belgium, this variation mainly occurs in mid-adulthood: the middle section of the «bathtub», in which mortality is minimal, may be extended or contracted, and the age at which mortality rates begin rise may be brought forward or postponed. Nonetheless, the particular manner in which this occurs will depend on the particular constellation of local conditions, which together create the conditions for mortality to be low.

In order to identify such differences, and to understand why, and under which conditions, they occur, life tables are indispensable, but the agespecific mortality rates required for computing the life tables may not necessarily be available. This is particularly true for small and mediumsized populations (under 50'000 or even larger in low-mortality populations, see Scherbov, Ediev, 2011) which are likely to have zero or very small numbers of deaths in young and young-adult age groups. Indirect standardisation cannot help here, as multiplying a standard mortality 
schedule by a constant at all ages will produce a series of «nested bathtubs» ${ }^{2}$ which do not correspond to the true shape of the unobserved mortality curves. If our mortality estimation remains at the level of the local, small area population, there is clearly no way out of this impasse.

One solution may be to aggregate populations spatially (Sun, Wong, 2016) or in terms of known characteristics (urban, suburban and rural; poor, middle class and rich; secular versus religious or by religious denomination; long established, veteran, versus new, migratory, populations). Such aggregations, however, while creating units of analysis that are homogeneous across one dimension, are likely to maintain internal heterogeneity across other dimensions. On the other hand, aggregating across a number of dimensions simultaneously is liable to leave us, once again, with populations which are too small for reliable estimation. Furthermore, the results of this aggregation itself may vary according to the way in which the aggregated units are defined: the «modifiable area unit problem», an issue over which we may have very little control given that data aggregations are defined administratively and not in terms of either explanatory or outcome variables (Nelson, Brewer, 2017).

Alternately, we may aggregate over time, counting deaths over a number of years and relating these to an estimate of the average population based, for instance, on a census count of the population at mid-period. By extending the period of aggregation, we can ensure an adequate number of counts in each cell, but this, too, is not without its costs. Mortality is a dynamic process and over time the total risk, and that at any age, will change. There is consequently a constant trade-off between the statistical errors to be reduced by extending the time span, and the substantive errors derived from its extension.

A different way to overcome these obstacles may be to use multilevel modelling to estimate mortality in a number of units simultaneously, as a function of local level social conditions, treating age group and the locality (possibly nested within a broader locality) as random effects (Pinheiro, Bates, 2004; Bates et al., 2015). Such an approach will allow for the com-

2. A bathtub curve, in reliability theory, is any hazard function composed of an initial burn-in period of declining failure rates, a central period of useful life, often with random failure, and a late, wear out period, in which the hazard increases over time (Klutke et al., 2003). Nested bathtubs, as the name implies, is a series of such hazard functions differentiated by a constant multiplier, so that the distance between any two curves is constant over the whole of the lifespan. I am grateful to Barbara Anderson for this metaphor. 
mon effects of age and local population on the risk of death, while modelling specifically the effects of local conditions, including the total level of mortality, and the effects these have on the different age groups (Lerch et al., 2017). Through such borrowing from strength (Congdon, 2014) we may be able to increase statistical reliability as well as reduce the number of parameters estimated.

The present analysis combines these different approaches, and uses them to analyse differential mortality within Begium. We use numbers of deaths, by sex and 5-year age groups, for six years around the 2001 census; and aggregate the population into 87 administratively defined spatial units, which are distinguished by region (Brussels, Flanders, Wallonia); by type (urban, peri-urban) and mean level of social characteristics. We thus build on the considerable knowledge we already have concerning what the relevant social characteristics are and, by constructing local area lifetables for these 87 local areas, consider how the specific shape of the mortality curve varies as mortality declines under different social conditions.

\section{The setting: Belgian arrondissements}

\section{Belgian mortality}

There has been no shortage of previous analyses of Belgian mortality differentials. However, most of these have focussed on the total mortality in the population, either as a whole or subdivided by sex (see, e. g. Van Houte-Minet, Wunsch, 1978; Poulain et al., 1984; Decroly, Grimmeau, 1991; Lagasse et al., 1990; Duchêne, Thiltgès, 1993; Joosens, Kesteloot, 1996; Deboosere, Gadeyne, 2002; Van Oyen et al. 2002; Bossuyt et al., 2004; Eggericx, Sanderson, 2007; Grimmeau et al., 2012a; Renard et al., 2015; Van Hemelrijck et al., 2017). The results of these analyses are remarkably consistent:

- Mortality in Wallonia is higher than in Flanders, with the Brussels Capital Region being intermediate but tending to similarity with the Flemish region.

- These differences have been apparent at least since the mid-twentieth century, even before the collapse of heavy industry and the economic decline of Wallonia.

- Mortality is closely associated with standards of living and levels of education, at the personal and the community level, and Flanders has 
a clear advantage on both of these scales. Controlling for this advantage mutes the regional differences, but does not efface them.

- Intra-regional differences exist, but these are secondary to the interregional differences. The only consistent exception is the province of Brabant Wallon to the south of Brussels, whose social conditions and mortality levels are closer to those of Flanders than to the rest of Wallonia.

- These differences hold for males more than for females, but the pattern of regional difference is similar for the two sexes. At the same time, male-female differences are considerably greater than the regional differences.

The advent of multilevel modelling in recent years has enabled researchers to disentangle individual from local area effects, whether of total mortality levels (Van Hemelrijck et al. 2016), or of particular causes of death (Hagedoorn et al. 2016a; Hagedoorn et al., 2016b). All these analyses, however, have focussed on death at all ages, or within a very broad age group, and have not considered the manner in which mortality is distributed across ages. Our purpose is to consider precisely whether mortality patterns are the same for males as they are for females; and whether a change in total mortality necessarily involves the same shift in the age patterning of mortality. In other words, we shall take the social structuring of mortality and its relation to social conditions as given, and consider how this structuring affects the age distribution of death rates, as mortality declines.

\section{The units of analysis}

Belgium is divided socially and administratively into three Regions: Flanders, Wallonia and the Brussels Capital Region. These are further divided into 43 administrative arrondissements, or divisions, of which one, the Brussels Capital Region, is composed of 19 communes, or municipalities. Of the others, 20 are in Wallonia and 22 are in Flanders. We subdivided about a half of the Flemish and Walloon arrondissements into regional urban centres and the surrounding peri-urban hinterlands. Altogether, we have 87 zones, divided into 45 Peri-Urban and 42 Urban zones, including the 19 Brussels communes. Figure 1 maps these divisions. These units, or zones, have a median population of about 100,000 per zone ( $50^{\prime} 000$ women; 47' 500 men). Total population at the census in 2001 was $10^{\prime} 295^{\prime} 724$. We registered all deaths for the sexennium around the census, from 1999 to 2004, during which time there were 627'881 deaths, to give an annual Crude Death Rate of 10.2/1000. 
Figure 1 Belgian arrondissements, divided into urban and peri-urban (semi rural) zones

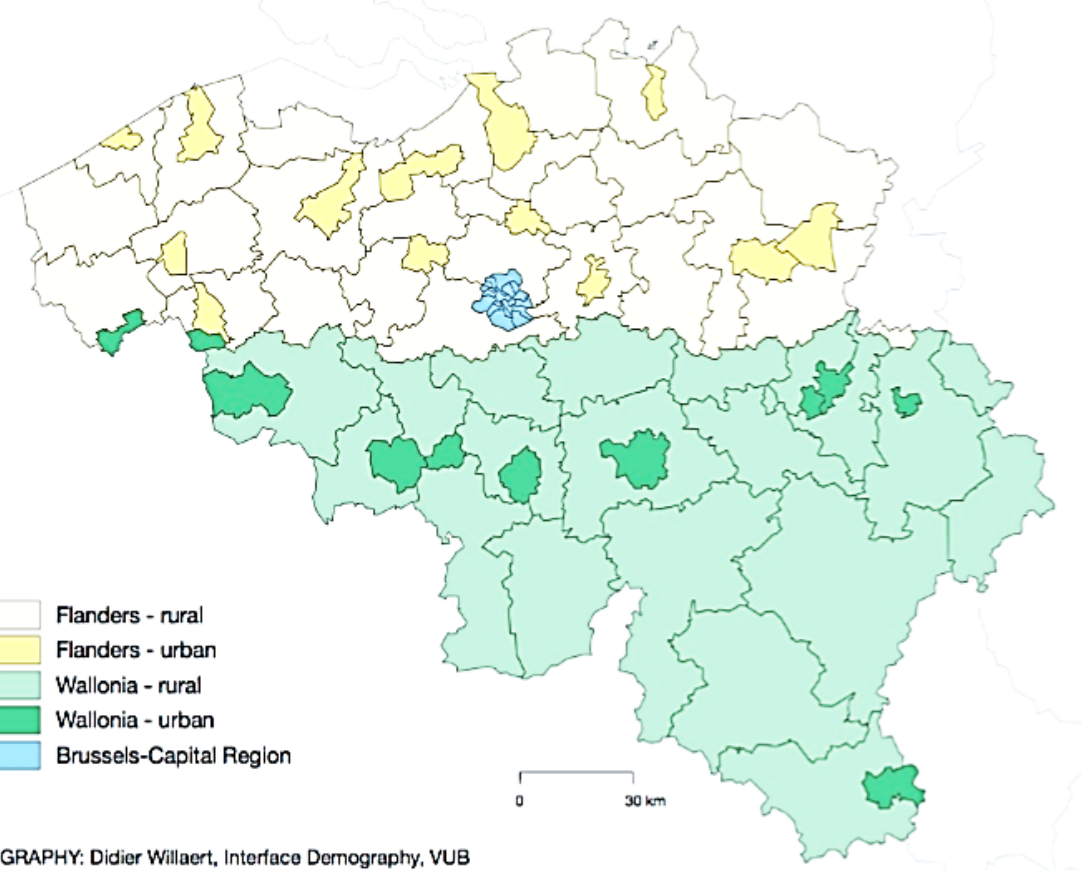

Social data

We used data from the census of 2001 and from Statistics Belgium to create measures of the social conditions pertaining in these geographical units:

- Deprivation: Following the logic of the Townsend Index (Townsend et al., 1988), we combined census information on the percent of the working age population unemployed; the percentage of households without a car and percentage of non-owner occupier households to create a scale of Deprivation ( $a=0.949)$. The proportion living in overcrowded conditions (less than 1 room per person) which was the fourth variable in the original Townsend Index did not correlate closely with the other variables and was excluded from the scale. Scores ranged from -1.46 (low deprivation) to 2.96 (high deprivation), $\bar{x}=0$ and $s=0.953$.

- Education: We computed the proportion of the population in each zone with a University degree (Cycle $1=$ BA, Cycle 2 = MA, or Doctorate). In view of the highly skewed nature of this distribution (median 
$=7.68$, mean $=10.1$ ) we used the logit of this proportion, with a range of -3.18 to $-0.634, \bar{x}=-2.33$ and $s=0.592$. For analysis, the variable was centred at the mean.

- Average Income per capita. Ranges from 6.2 to 14.6 thousand euros, with $\bar{x}=11.5$ and $\mathrm{s}=1.63$, For analysis, the variable was centred at the mean.

- Marital Status. From the census data on household composition, we computed the percentage of married-couple households with or without children, as a gross estimate of the household structure of the population. This percentage correlated -0.992 (!) with the percentage of single-person households, other possibilities being unmarried couples with or without children, single-parent households, or other (composite) households. We thus have a measure of the extent to which the household structure in the population is one of traditional married couples, with or without children, depending on their stage in the life cycle. The percentage of married households ranged from $19.9 \%$ to $65.4 \%, \bar{x}=47.7$ and $\mathrm{s}=10.8$. For analysis, this was converted to logit and centred at the mean.

Figure 2 presents boxplots of these four indicators by Region (Flanders, Brussels and Wallonia) and type: Urban or Peri-Urban. The three regions are clearly distinguished in their social composition: Deprivation scores are higher in Urban than in Peri-Urban zones, and higher in Wallonia than in Flanders. They are particularly high in Urban Brussels. By contrast, University education is particularly high in Brussels, and higher in the Flemish Urban than in the Peri-Urban or Walloon zones. We note that the Brussels hinterland (Leuven (Urban) and Leuven (Peri-Urban) in Flanders, East and West Nivelles in Wallonia) are more similar in education to Brussels than to their own respective Regions. Income, on the other hand, is higher in Flanders than in Brussels and Wallonia, and very broadly distributed in the Brussels Urban zones, which have both very high (Sint-Pieters-Woluve) and very low (Sint-Joost-Ten-Node) incomes. 
FIGURE 2 Social characteristics of arrondissements, by region and type

a. Deprivation

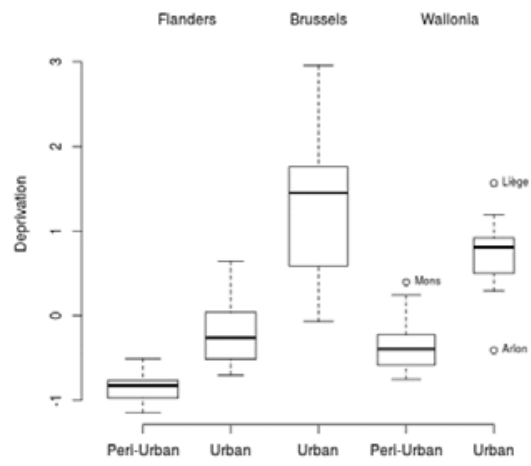

c. Average per capita income

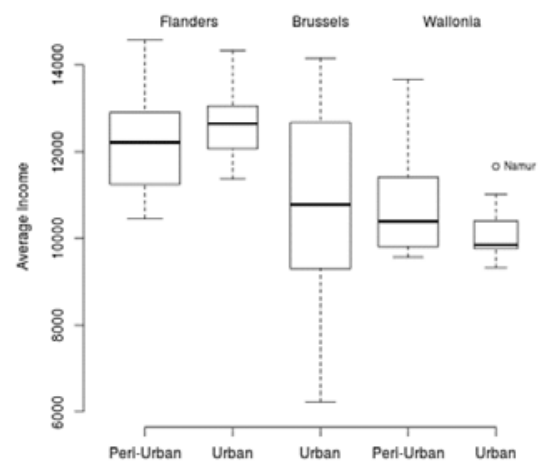

b. University education

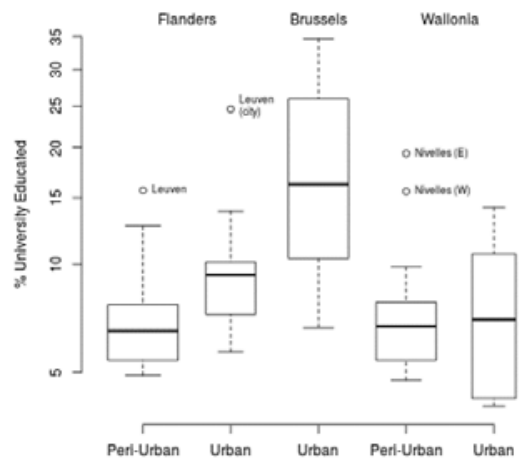

d. Household structure

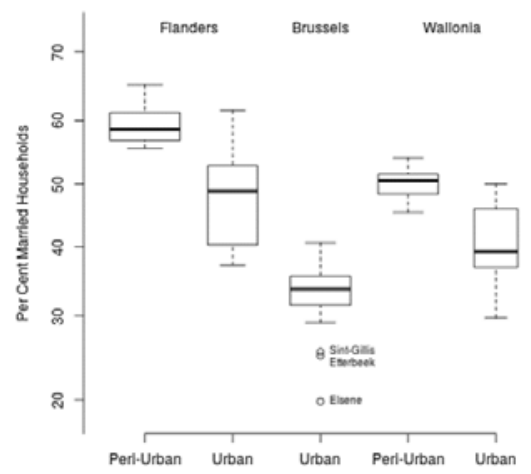

Household structure, the proportion of Married-Couple Households, is the inverse of the Deprivation score: Two of the variables, Deprivation and Married-Couple Households (Household structure) are very closely correlated $(r=-0.916)$ and this is also reflected in their geographic distribution. There is a higher proportion of Married-Couple households in rural than in urban areas, a higher proportion in Flanders than in Wallonia, and a very low proportion in Brussels. By contrast, urban areas have higher Deprivation scores than do the more rural areas, and Deprivation is more prevalent in Wallonia than in Flanders and is highest in Brussels. In part, this may be a result of the relationship between these variables and the conditions of urban living in Belgium. Thus, in the Deprivation score, car and home ownership, are consistently associated with higher standards of living, but both have been shown to decline with urban density (see, e.g. Van Acker, Witlox, 2010; Xhignesse et al., 2014). Thus, despite its apparent face validity, in practice it may be difficult to interpret 
the Deprivation variable. Given that we cannot include both the Deprivation and the Household Structure variables in our model, we shall include the latter, together with average Income and University education as measures of social hierarchy, and a dummy variable for the Urban-PeriUrban distinction. However, given the high collinearity, it must be borne in mind that the Proportion Married is as much a measure of material deprivation as it is of household structure.

\section{Standardised Mortality}

FIGURE 3 Standardised mortality ratios (SMR)

a. Distribution of male and female SMR

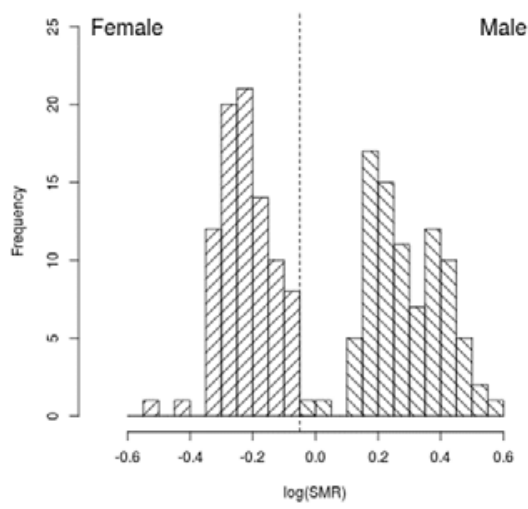

b. Male and female SMR, by region

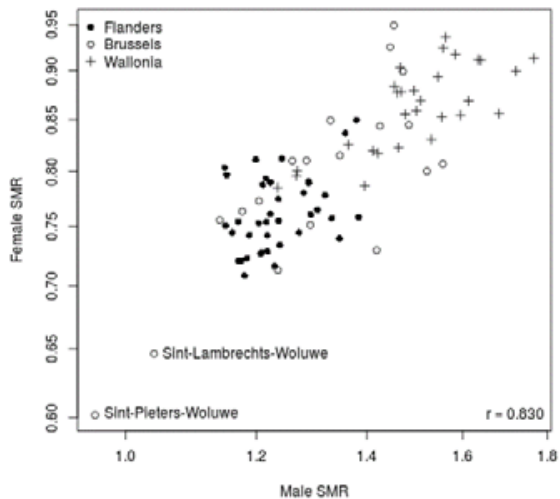

As a first step, we calculated the indirect standardised mortality ratio (SMR) for male and female mortality in the 87 zones, based on the agespecific total mortality rate for Belgium over the six years 1999 to 2004 . Figure 3(a) presents the distribution of the male and female values (logged for symmetry). As can be seen, there is no overlap, and only one male value (Sint-Pieters-Woluwe in Brussels) approaches (but does not actually cross over) into the female range. The distributions are similar though the female values show a greater concentration around the mean. Figure 3(b) plots the female against the male values, identifying the points by Region. There is a close correlation between the two values ( $\mathrm{R}^{2}$ $=0.689$ ) and a clear distinction between Flemish zones which have lower SMR values for both males and for females than do the Walloon zones, with almost no overlap. The Brussels zones are more spread out than are the Flemish ones, but, taken as a whole, SMR is still lower in Brussels than in the Walloon zones. 


\section{Analysis}

\section{Reproducing SMR values}

Table 1 models the SMR values using a multi-level Poisson GLM model of the total number of observed deaths in each zone, by sex, with observations by sex nested within the zones, and the number of observed deaths offset by the (log) number of expected deaths. The baseline model includes the female advantage as given, and random variation between the zones. The standardised male mortality risk is $66 \%$ higher than the female mortality risk.

TABLE 1 Modelling SMR as a function of social conditions

\begin{tabular}{|c|c|c|c|c|}
\hline \multirow{2}{*}{ Variable } & \multirow{2}{*}{ Base model } & \multirow{2}{*}{ Fixed effects } & \multicolumn{2}{|c|}{ Interaction with sex } \\
\hline & & & Males & Females \\
\hline Intercept & 0.802 & 0.790 & 1.29 & 0.803 \\
\hline Sex: Male & 1.66 & 1.66 & & \\
\hline $\begin{array}{l}\text { Married households } \\
\text { (centred at mean) }\end{array}$ & & 0.861 & 0.837 & 0.885 \\
\hline $\begin{array}{l}\text { University education } \\
\text { (centred at mean) }\end{array}$ & & 0.905 & 0.879 & 0.929 \\
\hline $\begin{array}{l}\text { Urban Zone } \\
\text { (baseline = peri-urban) }\end{array}$ & & $0.968^{*}$ & $0.983^{\circ}$ & $0.953^{* *}$ \\
\hline $\begin{array}{l}\text { Region: Wallonia } \\
\text { (baseline = Flanders/Brussels) }\end{array}$ & & 1.10 & 1.13 & 1.07 \\
\hline Variance (zones) & 0.00932 & 0.00210 & \multicolumn{2}{|c|}{0.00212} \\
\hline Deviance gain (df) & $2^{\prime} 871(171)$ & $121(4)$ & \multicolumn{2}{|c|}{$409(4)$} \\
\hline
\end{tabular}

Model 2, the Fixed Effects model, introduces fixed effects for zone properties: University Education, Proportion Married and Urbanisation. With these included, average Income made no substantive contribution and was dropped from the model. Males maintain their disadvantage; traditional family structure (Married Couple Households) reduces mortality by about $14 \%$ for each unit on the scale; education reduces mortality by about $10 \%$ for each unit on the logit(University Education) scale; Urban areas have about 3\% lower mortality than comparable Peri-Urban zones and Wallonia has about $10 \%$ higher mortality than Flanders or Brussels. We note that the introduction of area-specific fixed effects reduces variation between the zones to less than a quarter of its previous level. 
Model 3 introduces interactions of the zone-level fixed effects with the sex of the population - male or female. Substantively, the male and female values do not differ greatly, but we note that the effect of social conditions is consistently greater for males than for females, except for the Urban Peri-Urban comparison. The interaction does reduce the model deviance, but, as we have introduced no further information concerning the local zones, it is not surprising that this model does not reduce the betweenzones variation any further. This model reproduces the observed SMR values almost perfectly: if we divide the fitted numbers of deaths from model 3 by the expected number of deaths to create fitted SMR values, these correlate almost perfectly (0.995) with the original SMR values (both series logged). We thus treat the reproduced SMR values as a correction on the original and in the rest of this paper will use the predicted SMR values.

\section{Estimating area-specific life tables}

There are clearly important mortality differences between the different zones we are analysing, both within and between the three major Regions. This does not mean, however, that the pattern of mortality is consistent across all the zones, but the raw data at our disposal do not enable us to compute reliable life tables. Accordingly, we estimated the number of deaths by age, sex and zone using a multi-level Poisson model with the (log) observed population as offset (multiplied by six as we have six years of mortality data). At level 2 we have random variations by zone (untapped characteristics), and initial random variations by age and sex, to reproduce the shape of the mortality curve. Subsequent models introduce interactions of region (Flanders/Brussels and Wallonia) and urbanisation (Urban/Peri-Urban type) with age and sex, and interactions of $\log (\mathrm{SMR})$ with age and sex. The first interaction allows for different mortality curves by region and urbanisation; the second for changes in the shape of the mortality curve as total mortality increases or decreases.

Table 2 presents the analysis for the different phases of this model. The base model allows for a fixed effect by sex (males almost double the risk of females), random variations by age and sex as well as by zone. The nested bathtubs model introduces fixed effects for social conditions, Married Households (family structure), University education and Urbanisation, by sex, and, at Level 2, interactions of region and urbanisation, by sex, with age. We are thus allowing for social conditions, as reflected in the level of total mortality, to increase or decrease age-specific mortality uniformly across the age range (nested bathtubs), and we are allowing 
for differences in the age pattern of mortality in Wallonia, as compared with Flanders and Brussels, and in Urban versus Peri-Urban zones. We see that the fixed effects for males and females have increased but male baseline mortality remains almost double the female baseline. With the exception (again) of urbanisation, social differences have a greater effect on male than on female mortality. We shall explore sex differences in the random effects below. The inter-zone variation in model 1 has been completely absorbed in the fixed and random effects, and has been removed (hence 0 in parentheses).

TABLE 2 Multilevel model of deaths by sex, age and zone characteristics

\begin{tabular}{|c|c|c|c|c|c|c|}
\hline Variable & \multicolumn{2}{|c|}{ Base Model } & \multicolumn{2}{|c|}{$\begin{array}{c}\text { Fixed effects } \\
\text { (nested bathtubs) }\end{array}$} & \multicolumn{2}{|c|}{ Interaction with sex } \\
\hline Fixed effects & Males & Females & Males & Females & Males & Females \\
\hline Intercept & 0.00751 & 0.00432 & 0.00719 & 0.00417 & 0.0104 & 0.00683 \\
\hline $\begin{array}{l}\text { Married households } \\
\text { (centred at mean) }\end{array}$ & & & 0.840 & 0.912 & $1.02^{\dagger}$ & $\left.1.02^{*}\right)$ \\
\hline $\begin{array}{l}\text { University education } \\
\text { (centred at mean) }\end{array}$ & & & 0.893 & 0.936 & $1.02 * *$ & $0.998^{\circ}$ \\
\hline $\begin{array}{l}\text { Urban zone } \\
\text { (baseline = peri-urban) }\end{array}$ & & & $0.990^{\circ}$ & $1.06^{+}$ & $0.925^{\circ}$ & $0.985^{\circ}$ \\
\hline $\begin{array}{l}\text { Region: Wallonia } \\
\text { (baseline = Flanders/Brussels) }\end{array}$ & & & 1.17 & $1.07^{* *}$ & $1.09^{* *}$ & 0.999 \\
\hline Random effects & Males & Females & Males & Females & Males & Females \\
\hline Variance (zones) & \multicolumn{2}{|c|}{0.00944} & \multicolumn{2}{|c|}{ (0) } & \multicolumn{2}{|c|}{ (0) } \\
\hline Age & 6.13 & 6.61 & 6.40 & 6.78 & 6.70 & 6.98 \\
\hline Age * Flanders (base) & & & 0 & 0 & 0 & 0 \\
\hline Age * Wallonia & & & 0.0234 & 0.0144 & 0.0141 & 0.00329 \\
\hline Age * Peri-urban (base) & & & 0 & 0 & 0 & 0 \\
\hline Age * Urban & & & 0.0168 & 0.0206 & 0.0216 & 0.0355 \\
\hline Age $* \log (S M R)$ & & & & & 1.34 & 1.16 \\
\hline Deviance gain (df) & \multicolumn{2}{|c|}{$31^{\prime} 422\left(3^{\prime} 822\right)$} & \multicolumn{2}{|c|}{$2^{\prime} 258$ (25) } & \multicolumn{2}{|c|}{ 1'464 (15) } \\
\hline
\end{tabular}

The latest model allows for changes in the shape of the mortality curve as the level of mortality changes, by introducing a random-level interaction between $\log ($ SMR), sex and age. The fixed effect coefficients are small or non-significant, and a number of them have changed direction. Most of the differentiation between the mortality curves derives from the changing shape of the curve as the general level of mortality (SMR) increases or decreases. We note also that the variation due to changes in SMR is considerably greater than that due to Region or Urbanisation. The global 
change reflected in the fixed effects is extremely small, and mostly appears to complement the age-specific changes reflected in the random effects.

In practice, this last model provides an almost perfect reproduction of the observed mortality rates: leaving out observations with zero deaths or observed mortality rates greater than 1 , the squared correlation between the log observed and reproduced values was 0.985 and the difference between the observed and predicted rate was not significant (details not shown). Of the 95 cells with no deaths in the observation period, the imputed mortality rate was less than 0.0005 in $88(92.6 \%)$ and greater than 0.001 in only four $(4.2 \%)$ of cases. For the 40 cells with mortality rates greater than 1 (of which 27 had zero populations, adjusted to 0.1 ) the imputed mortality rates were symmetrically distributed around a me$\mathrm{dian} /$ mean of 0.53 . We may thus conclude that the model is not only faithfully reproducing credible mortality rates (in the range of 0 to 1 ) it is also imputing plausible values to those cells in which the observed rates are faulted by having no observed deaths or too small an observed population.

Figure 4 shows the random deviations, by sex and age, associated with changes in SMR, or total mortality. If the curve maintained the same shape, then as mortality (SMR) increases or decreases, the mortality curve would move up or down on the y-axis (the log (mortality rate)). However, curves at different levels of mortality are not simple «nested bathtubs», and the shape of the curve necessarily changes, as deaths are delayed and occur later in life. The random effects indicate how the shape of the curve changes, by indicating the ages at which the mortality increase is accelerated or decelerated with the increase/decrease in SMR.

For both males and females, the main effects are to be seen in mid- to lateadulthood, between the ages of (approximately) 30 and 70. A decrease in mortality is thus associated with an extension of the period of minimum rates and a decline in premature mortality, an effect which is accentuated for females. A secondary effect is notable, in particular for males, namely, a small relative decrease in mortality in the teens and early 20 's as the level of mortality rises. In other words, the change in mortality leaves the mortality hump largely unaffected, suggesting that the origins of the hump are to be found in a separate process, which is independent of the general rise or fall in the level of mortality. 
FIgURE 4 Mortality deviations by age and sex

a. SMR

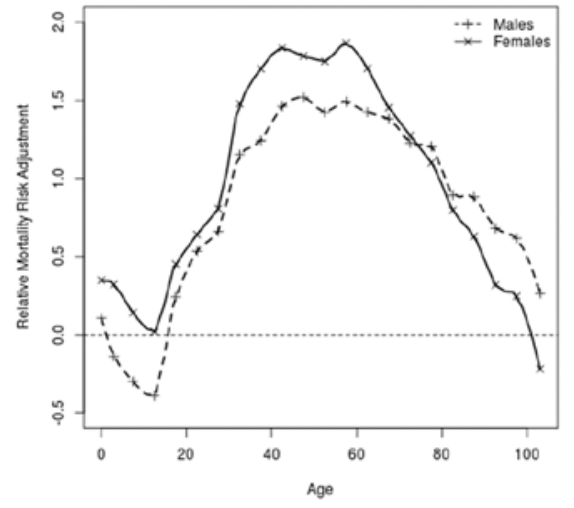

b. Wallonia and urban
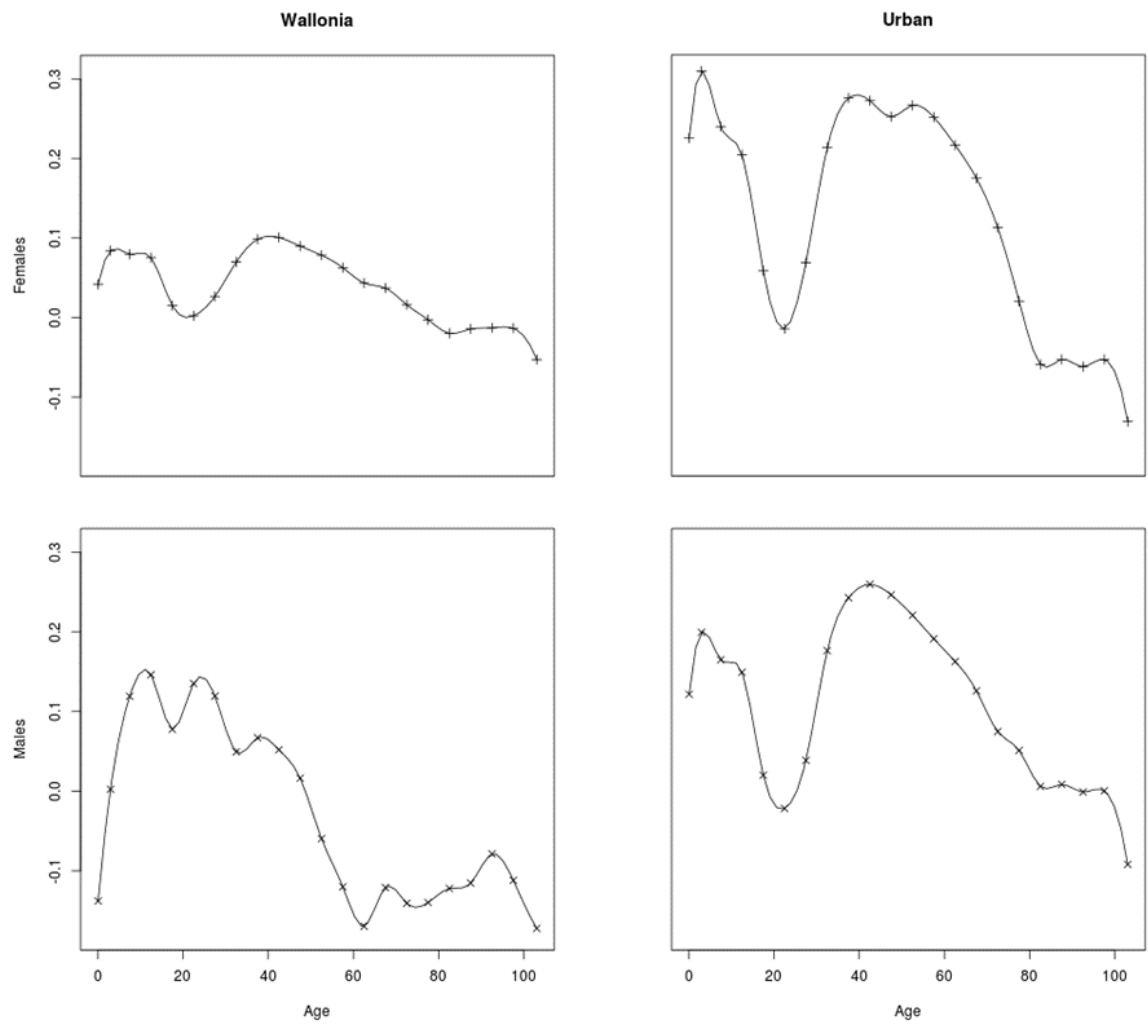
Figure $3 \mathrm{~b}$ shows the deviations, on a very different scale, by age and sex, for Wallonia, compared with Flanders and Brussels; and for Urban, compared with Peri-Urban zones. Compared with their neighbours to the north, females in Wallonia have almost the same mortality pattern: marginally higher below age 20 and around age 40, slightly lower at very old ages. By contrast, males have higher mortality at younger ages, lower at older ages. The urban patterns, by contrast, are the same for males as for females: higher mortality at very young ages and in mid-adulthood, lower mortality at older ages. It is important to note that these differences are small when compared with the effects of SMR changes on the pattern of mortality.

\section{Comparison with SMR based life tables}

Having now estimated local level life tables, let us see how they differ from the life tables we would obtain by simply multiplying the national mortality rates by the local, sex-specific, SMR. Clearly, if the two do not differ either in life expectancy at birth, nor in the details of the mortality curve at various ages, then there is nothing to be gained from a sophisticated estimation technique and we are better off with the SMR based estimate. Apart from $\mathrm{e}_{0}$ we focus on three specific measures:

- The life-table modal age at death (M) in the adult population. If the mortality curve in mature and late adulthood is approximately Gompertzian $\left(\mathrm{m}(\mathrm{x})=\mathrm{ab}^{\mathrm{x}}\right.$, with $\mathrm{m}(\mathrm{x})$ the rate of mortality at age $\mathrm{x}, a$ the rate at the starting age of the Gompertz function, $b$ the rate of population ageing and $x$ the number of years since the start of the Gompertz process), then $\mathrm{M}$ is strictly a function of $a$ and $b$ (Thatcher et al., 2010; Horiuchi et al., 2013; Missov et al., 2015). In other words, the mode is a reflection of the level and rate of increase in the mortality risk at older ages, and may thus be interpreted as a measure of the delay in the age at death at advanced ages. We estimate $M$ by nonlinear regression, using the formula proposed by Horiuchi et al. (2013),

$$
\mathrm{m}(\mathrm{x})=\mathrm{be}(\mathrm{x}-\mathrm{m})
$$

fitting over the age range 50 to 90 inclusive.

- The age at which the mortality rate attains five per 1000 (AFPT3). As mortality declines, so the level of mortality declines at all ages, and

3. Age at Five Per Thousand. 
the age at which any particular level of mortality is reached is pushed back. In low mortality populations, AFPT is in mid-adulthood, around age 50 , so that, if we control for total mortality, this can also serve as a measure of delayed adult mortality. We determine the age by fitting a spline curve to the log-mortality rates and interpolating to find the age at which $\log (\mathrm{m}(\mathrm{x}))=\log (0.005)$.

- Infant mortality (IMR, q0), long recognised as a major measure of social welfare. We use logit(q0), thus symmetrising both the distribution of observed values, and the observed effect: the logit of infant mortality is the negative of the logit of infant survivorship.

Figure 5 plots the SMR based values of life expectancy and these three measures against the model based values.

- Life expectancy at birth (Panel (a)): We see that the results are almost identical, though for low values of male $e_{0}$ the SMR-based values are slightly higher than their respective model-based values, and for females, the SMR-based values are consistently slightly lower. Overall, however, we may say that SMR-based life tables give effectively the same $\mathrm{e}_{0}$ estimates as do the model-based life tables.

- Modal age at death (Panel (b)): Here, too, the SMR- and model-based estimates are almost identical. As with life expectancy, male Modal values based on SMR are consistently higher than the model-based estimates of the modal age at death, whereas for female tables there is a slight tendency for the model-based values to be higher.

- The Age at which the Mortality Rate equals 5/1000 (AFPT, Panel (c)), correlates closely between the two estimates. This close correlation, however, is misleading. In the SMR-based estimate, moving the curve up and down in proportion as SMR changes naturally decreases or increases AFPT, but it does not change the shape of the curve. In the model-based estimates, as we saw above, a decline in total mortality is associated with an extension of the age-range over which mortality is minimal. Consequently, there is considerably more variation between high and low mortality curves than in the SMR based values. In fact, the range in the model-based estimates (excluding the two outliers, Woluwe-Sint-Pieter and Woluwe-Sint Lambert) is more than double that in the SMR based estimates, for males and females alike. The three regions follow, effectively, the same path, but as a result of the random Urban: age interaction, the Peri-Urban model-based estimates are slightly higher than the comparable Urban estimates.

Thus, as social conditions improve and mortality declines, the mortality curve shifts down slightly, naturally increasing AFPT. More importantly, however, it flattens out, further delaying the age at which 
senescent mortality begins to rise and further increasing the AFPT. Furthermore, female curves have an extra 5 years delay or more in AFPT, irrespective of the level of mortality, implying a flatter curve and greater delay in senescent mortality than for men.

FIGURE 5 Life table characteristics: SMR-based versus model-based estimation

a. Life expectancy

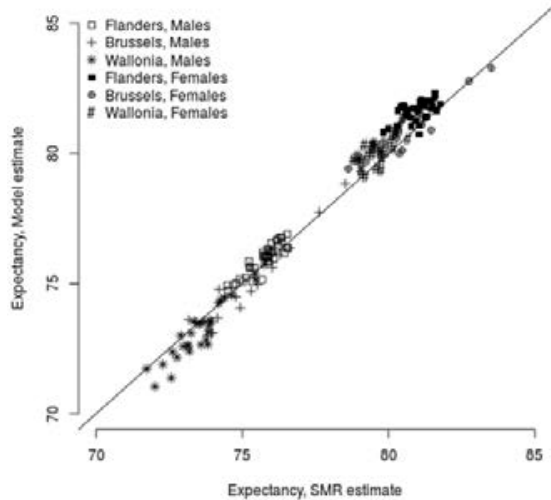

c. Age at five per thousand (AFPT)

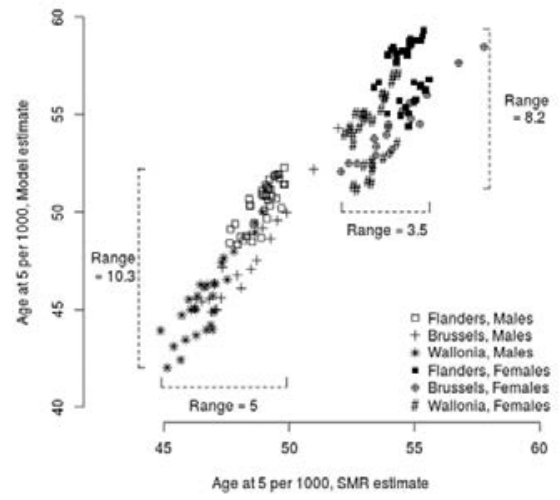

b. Modal age at death

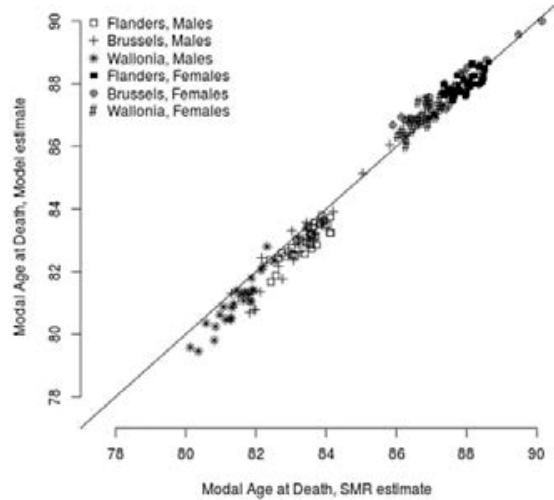

d. Infant mortality

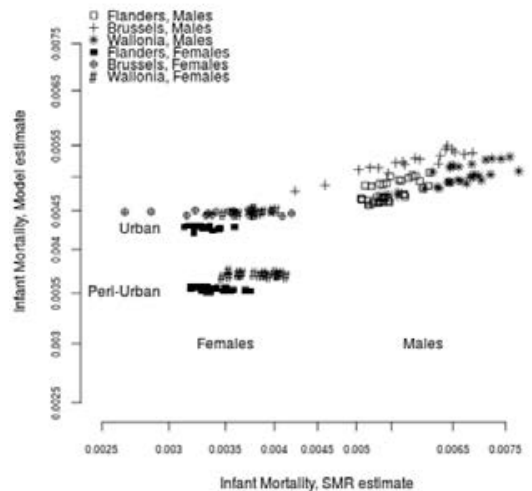

- Infant mortality (Panel (d)): This result is the most surprising of all. An SMR based life table will naturally multiply the national level of infant mortality by the value of SMR, so that infant mortality will necessarily appear to decline as mortality declines. The model-based estimates suggest that this may not necessarily be the case. For males, infant mortality rises with total mortality, but far more slowly than it does in the SMR-based tables, and it is consistently lower in the model than in the SMR based estimates. In particular, for any given level of SMR-based IMR, it is lower in Peri-Urban than in Urban areas, and 
slightly higher in Brussels than elsewhere. For female infant mortality values, which are consistently lower than the male values, there is a constant value of infant mortality, irrespective of the level of mortality. This value is slightly lower for Peri-Urban than for Urban areas, and marginally lower in Flanders than in Wallonia or Brussels. Alternative modelling of the tables (simple GLM including a sex:age:SMR interaction with no random effects, or a simple GLM of the three first age groups only) gave effectively the same results (details not shown). The explanation is to be found in the raw age- 0 mortality rates by SMR (details not shown) in which the female mortality rates bear no relation to SMR, and male mortality rates rise only slightly as SMR rises. We do note, however, that in the raw values there is considerably more variation around the trend line than in the modelbased estimates and considerably more variation in the male than in the female infant mortality rates.

If our only interest, then, is in a local measure of total mortality, we need look no further than the SMR, either comparing these values directly, or translating into life expectancies through calculation of life tables, on the basis of an estimated mortality curve obtained by multiplying the national schedule of mortality rates by the local, sex-specific, SMR. Such mortality curves, and the derived life tables, however, will fault on the details, such as the true level of infant mortality or the delay (or prematurity) of mid- or late-adulthood mortality. Thus, if we are interested in more nuanced information, for such purposes as projections and planning, or for understanding broader social processes, we need life tables which are more closely matched to the local age-specific mortality rates, and for this, the model-based life tables are indispensable.

\section{Discussion}

Local level mortality for small areas has, traditionally, been estimated by a single parameter reflecting the total level of mortality, by sex, such as the SMR of indirect standardisation. As mortality declines to historically unprecedented low levels, it becomes important to consider the finer details of the local mortality curve. These details have both practical and theoretical implications, as we have tried to show by focussing on a few of the details which make up the life table. This list could be extended to consider, for instance, the rate of ageing (the slope of the $\log$ (mortality) curve in older ages), which declines as SMR increases, but is, of course, constant under the SMR model. However, the paucity of deaths, especially 
at young ages, and even of population, at older ages, means that reliable mortality estimates cannot be obtained using local data alone. The multilevel model proposed here solves this problem by treating local mortality rates as deviations from the national average and enables the construction of credible life tables, which accord well with other measures of total mortality, even in situations where there are insufficient local data. The model also separates out global (fixed) effects of social differences, which operate at all ages, from interactive effects which operate differentially across the age range. Changing social conditions, such as household structures, mean levels of education and the level of urbanisation, are all directly associated with changes in the level of mortality. Wallonia, too, has a slightly higher level of mortality than that in Brussels or in Flanders. This higher mortality derives not so much from a universal increase in mortality at all ages, but in age specific changes which vary with the level of total mortality and with the specific sub-population at hand.

It is important to point out that these changes in the shape of the mortality curve occur within a particular national system, at a given general level of mortality. Over time, mortality declines have been concentrated in different age groups; childhood, infancy, young adulthood, old age, etc. The locus of change, in mid-adulthood, which we have identified in the current analysis, reflects one particular stage of mortality decline, and in no way purports to be a universal rule. On the other hand, a careful look at mortality rates in infancy, particularly for girls, suggests that they may be very loosely, if at all, related to classic measures of standard of living. This may be an artefact of data paucity - but note that in mid-life, where deaths are no more frequent than in infancy, a very clear story emerges, relating delayed mortality to mortality decline under improved social conditions. The flat infant mortality gradient may thus reflect conditions in a small country with good communications; universal education and an extensive, socialised, health care system, which ensures necessary interventions as and when needed.

The multilevel model used here is not, of course, unique, and there are a number of more, or less, sophisticated alternatives which could be used. On the one hand, given the lack of residual variation between the zones, we could have used a simple Poisson model, with the age by region, urbanisation and SMR interactions introduced as fixed effects. Initial analysis suggests that the results obtained are very similar to those reported above. Alternately, one could take a Bayesian (MCMC) approach, treating the estimates obtained here as starting points. However, as Hamra et al. (2013) point out, «in the absence of an informative prior, the two tech- 
niques will often return similar if not identical point and interval estimates for the parameters of interest» (p. 633). Nonetheless, «[w] hen the sample size becomes small, or a regression model becomes sufficiently complex, traditional asymptotic maximum-likelihood estimation may poorly estimate the parameter of interest» (ibid). At the same time, the variables used in the analysis have been limited, essentially, to issues of material and cultural capital (Bourdieu, 1986). There is clearly scope for extending the analysis to other demographic variables, such as fertility and migration patterns, as well as to behavioural variables such as diet (Grimmeau et al., 2012b).

The present analysis should thus be seen as an initial exploration, bringing out the possibility of identifying local level life tables for a small population within a larger, national system. Such an evaluation is considerably closer to the raw data than an estimate based on model life tables, or imputed life table parameters can be and, as we have seen, it helps identify important differences in the pattern of mortality under different social conditions. It offers, we suggest, a further step on the road to a full understanding of the patterning of mortality in a population, but considerable work remains to be done, replicating this analysis in other countries, under different social conditions and at different levels of mortality.

\section{Acknowledgments}

Parts of this paper were written while the author was a VLAC fellow at the Flemish Royal Academy (2012-3), and his work has also been assisted by funding from the Israel Science Foundation, grant 677/11. I am grateful to Patrick Deboosere and Didier Willaert of Interface Demography, VUB, who provided the data and for many discussions concerning the results. Previous versions of this paper have been presented, inter alia, at the Flemish Royal Academy (2013) and Chaire Quetelet (2015). I am also grateful to Michel Poulain, Guillaume Wunsch and other participants at these meetings for valuable comments. Naturally, I remain solely responsible for any remaining shortcomings in this paper. 


\section{References}

Anson J. (1988), "Mortality and Living Conditions: Relative Mortality Levels and their Relation to the Physical Quality of Life in Urban Populations», Social Science \& Medicine, 27 (9), pp. 901-910, https://doi.org/10.1016/0277-9536(88)90280-8.

Anson J. (1993), "The Shape of Mortality Curves: An Analysis of Counties in England and Wales, 1911», European Journal of Population, 9 (1), pp. 33-54, https://doi.org/ 10.1007/BF01267900.

Anson J. (2010), «Beyond Material Explanations: Family Solidarity and Mortality, a Small Area-level Analysis», Population and Development Review, 36 (1), pp. 27-45, https://doi.org/10.1111/j.1728-4457.2010.00316.x.

Bates D., Maechler M., Bolker B., Walker S. (2015), «Fitting Linear Mixed-Effects Models Using Ime4», Journal of Statistical Software, 67 (1), pp. 1-48, https://doi.org/ 10.18637/jss.v067.i01.

Bossuyt N., Gadeyne S., Deboosere P., van Oyen H. (2004), «Socio-Economic Inequalities in Health Expectancy in Belgium», Public Health, 118, pp. 3-10, https://doi.org/ 10.1016/S0033-3506(03)00130-6.

BOURDIEU P. (1986), "The Forms of Capital», J. RICHARDSON (ed), Handbook of Theory and Research for the Sociology of Education, New York, Greenwood, pp. 241-258.

Coale A. J., Demeny P., Vaughan B. (1983), Regional Model Life Tables and Stable Populations. New York, Academic Press.

Congdon P. (2014), «Estimating Life Expectancy in Small Areas, with an Application to Recent Changes in Life Expectancy in US Counties», J. ANSON, M. LUY (eds), Mortality in an International Perspective, Dordrecht, Springer, pp. 15-33, https://doi.org/ 10.1007/978-3-319-03029-6_2.

Deboosere P., Gadeyne S. (2002), «Can Regional Patterns of Mortality in Belgium be Explained by Individual Socio-Economic Characteristics?», Retrieved December 16, 2015 from www.cairn.info/article_p.php?ID_ARTICLE=RPVE_414_0087.

DeCroly J.-M., GrimmeaU J.-P. (1991), «Variations intercommunales de la mortalité par âge en Belgique», Espace, Populations, Sociétés, 9 (1), pp. 75-83, https://doi.org/ 10.3406/espos.1991.1445.

DUCHÊNE J., THILtgès E. (1993), «La mortalité des plus de 15 ans en Belgique : les disparités régionales en 1985-1987», Espace, Populations, Sociétés, 11 (1), pp.61-74, https://doi.org/10.3406/espos.1993.1556.

Eggerickx T., SANDERSON J.-P. (2007), "Les inégalités spatiales de mortalité en Belgique : 1980-2005», Démographie et Santé, 14ème Colloque National de Démographie de la CUDEP, Bordeaux, pp. 21-24.

Goldman N. (1980), "Far Eastern Patterns of Mortality», Population Studies, 34 (1), pp. 5-19, https://doi.org/10.1080/00324728.1980.10412832. 
Grimmeau J.-P., Decroly J.-M., Wertz I. (2012a), «La démographie des communes belges de 1980 à 2010", Courrier Hebdomadaire du CRISP, 37.

Grimmeau J.-P., Van Hecke E., Willaert D. (2012b), A Concise Geography of Belgium: Population, Ghent, Academia Press, pp. 26-31.

Hagedoorn P., Vandenheede H., Vanthomme K., Willaert D., Gadeyne S. (2016a), «A Cohort Study into Head and Neck Cancer Mortality in Belgium (2001-11): Are Individual Socioeconomic Differences Conditional on Area Deprivation?», Oral Oncology, 61, pp. 76-82, https://doi.org/10.1016/j.oraloncology.2016.08.014.

hagedoorn P., Vandenheede H., Willaert D., Vanthomme K., Gadeyne S. (2016b), «Regional Inequalities in Lung Cancer Mortality in Belgium at the Beginning of the 21st Century: The Contribution of Individual and Area-Level Socioeconomic Status and Industrial Exposure», PLoS ONE 11 (1), https://doi.org/10.1371/journal.pone. 0147099.

Hamra G., Maclehose R., Richardson G. (2013), "Markov Chain Monte Carlo: An Introduction for Epidemiologists», International Journal of Epidemiology, 42, pp. 627-634, https://doi.org/10.1093/ije/dyt043.

HoRiuchi S., Ouellette N., Cheung S. L. K., Robine J. M. (2013), «Modal Age at Death: Lifespan Indicator in the Era of Longevity Extension», Vienna Yearbook of Population Research, 11, pp. 37-69, https://doi.org/10.1553/populationyearbook2013s37.

Hystad P., Demers P. A., Johnson K. C., Carpiano R. M., Brauer M. (2013), «Long-Term Residential Exposure to Air Pollution and Lung Cancer Risk», Epidemiology, 24, pp. 762-772, https://doi.org/10.1097/EDE.0b013e3182949ae7.

Joosens J. V., Kesteloot H. (1996), «Mortality Trends in Belgium and The Netherlands: Closing the Gap», Acta Cardiologica, 51 (1), pp. 9-25.

lagasse R., Humblet P. C., Lenaerts A., Godin I., Moens F. G. (1990), «Health and Social Inequities in Belgium", Social Science and Medicine, 31 (3), pp. 237-248, https://doi. org/10.1016/0277-9536(90)90270-3.

LANGFORD I., BENTHAM G. (1996), «Regional Variations in Mortality Rates in Englnd and Wales: An Analysis Using Multi-Level Modelling», Social Science and Medicine, 42 (6), pp. 897-908, https://doi.org/10.1016/0277-9536(95)00188-3.

LeRCH M., OrIS M., WANNer P. (2017), «Periurbanization and the Transformation of the Urban Mortality Gradient in Switzerland», Population-E, 72 (1), pp. 93-122.

Mahoney M. C., Labrie D. S., Nasca P. C., Wolfgang P. E., Burnett W. (1990), «Population Density and Cancer Mortality Differentials in New York State, 1978-1982», International Journal of Epidemiology, 19 (3), pp. 483-490, https://doi.org/10.1093/ije/ 19.3.483.

Missov T. I., LenARt A., Nemeth L. et al. (2015), "The Gompertz Force of Mortality in Terms of the Modal Age at Death, Demographic Research, 32, Article 36, https://doi. org/10.4054/DemRes.2015.32.36. 
Nelson J. K., BREWER C. A. (2016), «Evaluating Data Stability in Aggregation Structures Across Spatial Scales: Revisiting the Modifiable Areal Unit Problem», Cartography and Geographic Information Science, 44 (1), pp. 35-50, https://doi.org/10.1080/ 15230406.2015.1093431.

NeWell C. (1988), Methods and Models in Demography, Chichester, Wiley.

Olshansky S., Ault A. (1986), "The Fourth Stage of the Epidemiologic Transition: The Age of Delayed Degenerative Diseases», The Milbank Quarterly, 64 (3), pp. 355-391, https://doi.org/10.2307/3350025.

OMran A. R. (1971), "The Epidemiologic Transition: A Theory of the Epidemiology of Population Change», The Milbank Memorial Fund Quarterly, 49 (4), pp. 509-538, https://doi.org/10.2307/3349375.

PETRIOLI L. (1982), Nouvelles tables-types de mortalite: application et population stable, Siena, Italy, Universita di Siena, Facolta di Scienze Economiche e Bancarie.

Pinheiro J. C., Bates D. M. (2015), Mixed Effect Models in S and S-Plus, NY, Springer.

Poulain M., Vandermotten C., Grimmeau J.-P., Colard A. (1984), «150 ans de dualité démographique en Belgique», Espace, Populations, Sociétés, 2 (1), pp. 137-154, https://doi.org/10.3406/espos.1984.947.

Renard F., Tafforeau J., Deboosere P. (2015), «Mapping the Cause-Specific Premature Mortality Reveals Large between-Districts Disparity in Belgium, 2003-2009», Archives of Public Health, 73 (13), 18 p.

RowLAND D. T. (2003)., Demographic Methods and Concepts, Oxford, Oxford University Press.

Santana P., Costa C., Marí-Dell'Olmo M., Gotsens M., Borrell C. (2015), «Mortality, Material Deprivation and Urbanization: Exploring the Social Patterns of a Metropolitan Area", International Journal for Equity in Health, 14 (55), https://doi.org/10. 1186/s12939-015-0182-y.

Scherbov S., Ediev D. (2011), «Significance of Life Table Estimates for Small Populations: Simulation-Based Study of Standard Errors», Demographic Research, 24 (22), pp. 527-550, https://doi.org/10.4054/DemRes.2011.24.22.

Shryock H. S., Siegel J. S. and Associates (1980), The Methods and Materials of Demography, Washington, D. C., U. S. Bureau of the Census.

Stanistreet D., Scott-Samuel A., Bellis M. A. (1990), «Income Inequality and Mortality in England», Journal of Public Health Medicine, 21 (2), pp. 205-207, https://doi. org/10.1093/pubmed/21.2.205.

Stanners G., Walsh D., McCartney G. (2015), "Is 'Excess' Mortality in Glasgow an Artefact of Measurement?», Public Health, 129 (6), pp. 684-690, https://doi.org/10. 1016/j.puhe.2015.02.032.

Sun M., Wong D. W. S. (2017), «Spatial Aggregation as a Means to Improve Attribute Reliability», Computers, Environment and Urban Systems, 65, pp. 15-27, https://doi. org/10.1016/j.compenvurbsys.2017.04.007. 
Thatcher A. R., SiU LAN K. C., Horiuch S. L. K., Robine J.-M. (2010), «The Compression of Deaths above the Mode», Demographic Research, 22, Article 17, pp. 505-538.

Townsend P., Phillimore P., Beattie A. (1988), Health and Deprivation: Inequality and the North, Routledge, London.

United Nations (1982), Model Life Tables for Developing Countries, NY, United Nations Publication, Sales No. E.81.XIII.7.

VAN ACKeR V., Witlox F. (2010), «Car Ownership as a Mediating Variable in Car Travel Behaviour Research Using a Structural Equation Modelling Approach to Identify Its Dual Relationship», Journal of Transport Geography, 18, pp. 65-74, https://doi.org/ 10.1016/j.jtrangeo.2009.05.006.

Van Hemelrijck W. M. J., Willaert D., Gadeyne S. (2016), «The Geographic Pattern of Belgian Mortality: Can Socio-Economic Characteristics Explain Area Differences?» Archives of Public Health, 74 (22), 10 p.

VAn Houte-Mınet M., Wunsch G. (1978), «La mortalié masculine aux Âges adultes : un essai d'analyse régionale», Population et Famille, 43 (1), pp. 37-68.

Van Oyen H., Bossuyt N., Deboosere P., Gadeyne S., Tafforeau J. (2002), «Differences in Health Expectancy Indicators in Belgium by Region", Archives of Public Health, 60, pp. 341-362.

Wilmoth J., ZUReick S., CANUdAS-Romo V. et al. (2012), «A Flexible Two-Dimensional Mortality Model for Use in Indirect Estimation», Population Studies, 66 (1), pp. 1-28, https://doi.org/10.1080/00324728.2011.611411.

Xhignesse G., BiAnchet B., Cools M. et al. (2014), «An Econometric Analysis of Homeownership Determinants in Belgium», B. Murgante, S. MisRA, A. M. A. C. RochA et al. (eds), Computational Science and Its Applications - ICCSA 2014, Cham, Switzerland, Springer, pp. 65-79, https://doi.org/10.1007/978-3-319-09150-1_6.

YeN I. H., KAPLAN G. A. (1999), «Neighborhood Social Environment and Risk of Death: Multilevel Evidence from the Alameda County Study, American Journal of Epidemiology, 149 (10), pp. 898-907, https://doi.org/10.1093/oxfordjournals.aje.a009733.

ZhaO Z., JoW-Ching E., ZhaO J. (2014), «Long-Term Mortality Changes in East Asia: Levels, Age Patterns, and Causes of Death», J. Anson, M. LUY (eds), Mortality in an International Perspective, Dordrecht, Springer, pp. 337-355, https://doi.org/10. 1007/978-3-319-03029-6_13. 